\title{
ChemComm
}

\section{Microporous polyurethane material for size selective heterogeneous catalysis of the Knoevenagel reaction $\dagger$}

52,7834

Received 25th March 2016, Accepted 19th May 2016

DOI: $10.1039 / c 6 c c 02578 a$

www.rsc.org/chemcomm

\author{
Sandeep Kumar Dey $\$$ Nader de Sousa Amadeu and Christoph Janiak*
}

The first polyurethane material which is microporous (BET surface area of $312 \mathrm{~m}^{2} \mathrm{~g}^{-1}$ ) is prepared by solvothermal synthesis and acts as highly efficient and recyclable heterogeneous catalyst in the Knoevenagel condensation showing size selectivity, and in the Henry reaction showing substrate selectivity under mild reaction conditions.

The development of functional porous organic frameworks (POFs) assembled from simple molecular building blocks has gained considerable attention in recent times, ${ }^{1}$ mainly because of their potential applications in gas storage and separation, ${ }^{2}$ catalysis, ${ }^{3}$ optoelectronics ${ }^{4}$ and nanotechnology. ${ }^{5}$ Considering a number of covalent linkages that can be derived by applying different synthetic reactions of a wide variety of molecular building blocks, it has become increasingly important to develop new functional POFs having high specific surface area, catalytically active pore surface, and remarkable chemical and thermal stability. Although impressive progress has been achieved in the field of heterogeneous catalysis using modified zeolites and metal-organic frameworks (MOFs), ${ }^{6}$ improving the functions of the pores in POFs for better catalytic performance and selectivity still remains a major challenge.

There has been, so far, no report on porous polyurethanes (Scheme 1) as catalysts, to the best of our knowledge.

The Knoevenagel condensation (Scheme 1) is one of the most useful and widely employed carbon-carbon bond formation reactions enjoying widespread application in synthetic organic chemistry for obtaining fine chemicals and heterocyclic compounds of biological importance. ${ }^{7}$ Several amine and amide

Institut für Anorganische Chemie und Strukturchemie, Heinrich-Heine-Universität Düsseldorf, 40204 Düsseldorf, Germany. E-mail: janiak@uni-duesseldorf.de; Fax: +49-211-81-12287; Tel: +49-211-81-12286

$\dagger$ Electronic supplementary information (ESI) available: FT-IR spectra, TGA curve, SEM images, EDX spectra and CHNS analysis of MPU and recycled MPU, and characterization of the MPU catalysed Knoevenagel and Henry reaction products by NMR. See DOI: 10.1039/c6cc02578a

\$ Research fellow funded by Alexander von Humboldt Foundation, D-53173 Bonn, Germany.

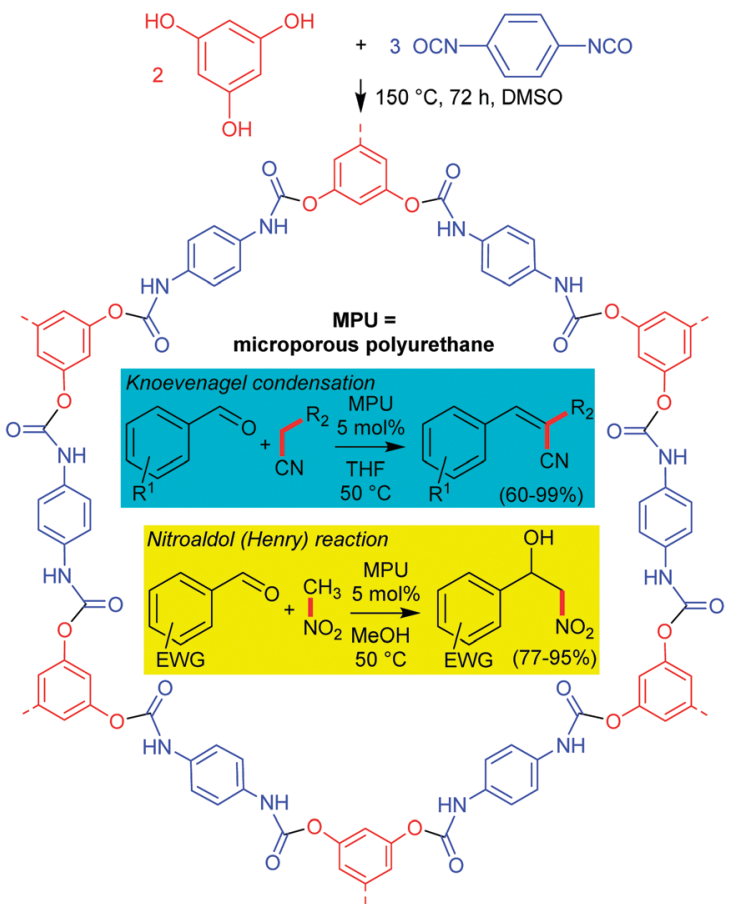

Scheme 1 Solvothermal synthesis of the microporous polyurethane (MPU) material, with the MPU catalysed Knoevenagel condensation reaction $\left(R_{1}=\right.$ various electron donating and withdrawing substituents, see Table 1 and $\mathrm{R}_{2}=-\mathrm{CN} /-\mathrm{COOMe}$ ) and the nitroaldol (Henry) reaction (EWG = electron withdrawing group, see Table 2) (product yields in parentheses).

functionalized MOFs have been employed as heterogeneous solid catalysts to promote both the Knoevenagel and Henry reactions and thus, addressing the problems of recyclability and high loading common with homogeneous base catalysts such as alkali metal hydroxides and organic amines. ${ }^{8}$ Further, a wide range of other porous solid catalysts have also been investigated for Knoevenagel reaction. ${ }^{9}$ Yet, only a couple of examples of POFcatalysed Knoevenagel reactions are known in literature. ${ }^{10}$ Its variant the nitroaldol (Henry) reaction (Scheme 1) has not been reported with POF catalysts, to the best of our knowledge. 
Porous polyurethanes have received considerable attention in recent years, because of their high elastance, biocompatibility and biodegradability essential for soft tissue engineering applications. ${ }^{11}$ They have also been used in enzyme immobilization and in biosensor applications. ${ }^{12}$ In our attempt to assess the, so far unknown catalytic activities of porous polyurethane, herein we report a new microporous polyurethane (MPU), synthesized by an unprecedented solvothermal route for MPUs, based on the condensation of phloroglucinol and 1,4-phenylenediisocyanate and its catalytic efficiency in the Knoevenagel and Henry reactions under mild conditions (Scheme 1). Due to its mild basic nature and ability to form hydrogen bonds, the urethane (carbamate) group can act as a catalytic driving force to prompt several important base-catalysed reactions.

The microporous polyurethane (MPU) material was synthesized solvothermally by the condensation of phloroglucinol and 1,4-phenylenediisocyanate in dimethyl sulfoxide at $150{ }^{\circ} \mathrm{C}$ (Scheme 1, see ESI $\dagger$ for details). The successful formation of the MPU was verified by Fourier transform infrared (FT-IR) and solid-state ${ }^{13} \mathrm{C}$ CP/MAS NMR spectroscopy. The FT-IR spectrum of the MPU showed disappearance of the stretching band of isocyanate $(\mathrm{N}=\mathrm{C}=\mathrm{O})$ at $2274 \mathrm{~cm}^{-1}$ and concomitant emergence of the carbonyl $(\mathrm{C}=\mathrm{O})$ stretching band at $1633 \mathrm{~cm}^{-1}$ (Fig. S2, ESI $\dagger$ ) indicating complete condensation between 1,4phenylenediisocyanate and phloroglucinol. Solid-state ${ }^{13} \mathrm{C}$ NMR spectrum further confirmed the presence of carbonyl carbon of the urethane moiety at $\delta=156 \mathrm{ppm}$, whereas other peaks at 150, 134,125 , and $109 \mathrm{ppm}$ were assigned to carbon atoms of the aryl rings (Fig. S3, ESI $\dagger$ ).

The PXRD pattern of the activated MPU (Fig. S4, ESI $\dagger$ ) indicated the partial ordered nature of the framework as reflected from the presence of several peak maxima in the diffractogram, notably in the $2 \theta$ range of $20^{\circ}$ to $30^{\circ}$ at $20.3^{\circ}(d=4.37 \AA), 21.4^{\circ}(d=4.14 \AA)$, $26.2^{\circ}(d=3.39 \AA), 27.8^{\circ}(d=3.20 \AA)$ and $29.9^{\circ}(d=2.99 \AA)$. SEM images revealed that the MPU crystallizes as small proliferated flakes, which are aggregated into an overall sponge like morphology (Fig. S5, ESI $\dagger$ ). The SEM images also showed the presence of scarcely distributed spherical particles, a likely indication towards the initial formation of the MPU spheres which eventually burst out forming the proliferated flakes during the solvothermal synthesis. Energy dispersive X-ray spectrometric (EDX) measurement showed the presence of sulfur which strongly suggests the inclusion of DMSO molecules within the pores of the framework (Fig. S6, ESI $\dagger$ ). CHNS analysis revealed the presence of $\sim 2.0 \mathrm{wt} \%$ of sulfur in the activated MPU, which accounts for $\sim 6.6 \mathrm{wt} \%$ of DMSO of the total weight of the polymer (Table S2, ESI $\dagger$ ). This result was supported by the thermogravimetric analysis (TGA) of the activated MPU, which showed $6.2 \%$ mass loss beginning at $180{ }^{\circ} \mathrm{C}$ till $280{ }^{\circ} \mathrm{C}$, beyond which the polymer starts to decompose (Fig. S7, ESI $\dagger$ ).

A nitrogen sorption measurement at $77 \mathrm{~K}$ showed permanent microporosity of the MPU with a BET surface area of $312 \mathrm{~m}^{2} \mathrm{~g}^{-1}$. The nitrogen sorption isotherm is a composite of Types I and II with an $\mathrm{H} 4$ hysteresis loop (Fig. 1a). The pronounced gas uptake at $P / P_{0}<0.10$ is associated with the filling of micropores. $\mathrm{H} 4$ loops are often found with aggregated crystals of zeolites, some
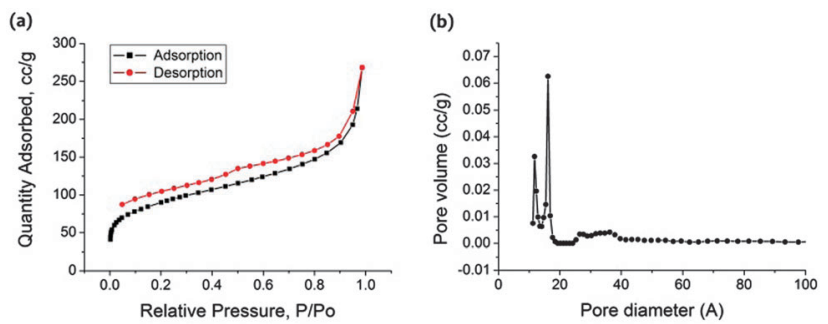

Fig. 1 (a) Nitrogen sorption isotherm at $77 \mathrm{~K}$, and (d) NLDFT pore size distribution curve of the activated MPU using a slit pore model.

mesoporous zeolites, and micro-mesoporous carbons. ${ }^{13}$ Non-local density functional theory $(\mathrm{NLDFT})^{14}$ pore size distribution using a slit pore model indicates that a significant fraction of the pores of the MPU originates from pores with a diameter less than $20 \AA$ (micropores by definition). ${ }^{13}$ Accordingly, the pore size distribution curve showed micropores centred at a diameter of $12 \AA$ and $16 \AA$, and a small fraction of mesopores between 20-40 A (Fig. 1b). Larger micropores of $16 \AA$ give a possible indication towards the formation of hexagonal pore structure in the MPU material, while smaller micropores of $12 \AA$ could be the result of hexagonal pore shrinking due to the inclusion of DMSO within the porous framework. The total pore volume was calculated to be $0.30 \mathrm{~cm}^{3} \mathrm{~g}^{-1}$.

Over the past few years, the use of POFs as heterogeneous catalyst for various organic reactions has been of continuous growing interest. ${ }^{3}$ For the Knoevenagel reaction, two 3D microporous imine-COFs (BF-COFs) have recently been shown to catalyse the condensation reaction in benzene with selectivity for benzaldehyde only. ${ }^{10 a}$ Further, an amide functionalized microporous organic polymer (Am-MOP) has also been shown to catalyse the Knoevenagel reaction in THF, albeit giving only three examples of benzaldehyde derivatives. ${ }^{10 b}$ A POF-catalysed Henry reaction has not been reported till date, to the best of our knowledge.

Encouraged by these results, the new MPU was assessed for its catalytic activity in the Knoevenagel reaction using a model reaction, wherein benzaldehyde reacts with malononitrile in the presence of $5 \mathrm{~mol} \%$ of activated MPU in tetrahydrofuran at $50{ }^{\circ} \mathrm{C}$ to give $98 \%$ yield of the desired $\alpha, \beta$-unsaturated product within $14 \mathrm{~h}$. In the absence of the MPU catalyst, only 5\% desired product was formed under the same optimal reactioncondition. The reaction when carried out at room temperature $\left(25{ }^{\circ} \mathrm{C}\right)$ did not proceed to completion, and yielded $90 \%$ of desired product even after $24 \mathrm{~h}$. The quantitative analysis of the Knoevenagel product formation was monitored by ${ }^{1} \mathrm{H}$ NMR spectroscopy at regular intervals of time. The detailed kinetic study showed that the MPU catalysed Knoevenagel reaction is completed within $14 \mathrm{~h}$ at $50{ }^{\circ} \mathrm{C}$ in THF (Fig. S15, ESI $\dagger$ ).

In general, excellent conversions above 95\% to the desired products were observed for most of the aromatic aldehyde substrates except for 9-anthracenecarboxaldehyde and biphenyl-4carboxaldehyde (Table 1). This suggests that the reaction occurs within the pores of the MPU which cannot possibly accommodate substrates of larger dimensions. Nevertheless, if the reaction 
Table 1 Catalytic data of MPU catalysed Knoevenagel condensation reactions

\begin{tabular}{|c|c|c|c|c|}
\hline \multirow{3}{*}{$\begin{array}{l}\text { Aromatic aldehydes } \\
\text { Benzaldehyde }\end{array}$} & \multicolumn{4}{|c|}{$\begin{array}{l}\text { Yield }(\%)[\mathrm{TON}]^{c} \text { of } \alpha, \beta \text {-unsaturated } \\
\text { product }\end{array}$} \\
\hline & \multicolumn{2}{|c|}{$\mathrm{R}^{2}=-\mathrm{CN}^{a}$} & \multicolumn{2}{|c|}{$\mathrm{R}^{2}=-\mathrm{COOMe}^{b}$} \\
\hline & 98 & {$[19.6]$} & 60 & {$[12.0]$} \\
\hline 4-Nitrobenzaldehyde & 99 & {$[19.8]$} & 95 & {$[19.0]$} \\
\hline 3-Nitrobenzaldehyde & 99 & {$[19.8]$} & 95 & {$[19.0]$} \\
\hline 2-Nitrobenzaldehyde & 99 & [19.8] & 90 & {$[18.0]$} \\
\hline 4-Carboxybenzaldehyde & 99 & [19.8] & 86 & {$[17.2]$} \\
\hline 4-Chlorobenzaldehyde & 97 & {$[19.4]$} & 89 & {$[17.8]$} \\
\hline 4-Fluorobenzaldehyde & 98 & {$[19.6]$} & 77 & {$[15.4]$} \\
\hline 4-Tolualdehyde & 95 & [19.0] & 63 & {$[12.6]$} \\
\hline 4-Anisaldehyde & 99 & [19.8] & 45 & {$[9.0]$} \\
\hline 2-Naphthalenealdehyde & 80 & {$[16.0]$} & 75 & {$[15.0]$} \\
\hline 9-Anthracenealdehyde & 0 & {$[0]$} & 0 & [0] \\
\hline Biphenyl-4-carboxaldehyde & 0 & {$[0]$} & 0 & [0] \\
\hline
\end{tabular}

${ }^{a}$ General conditions: aldehyde $(1.0 \mathrm{mmol})$, malononitrile $(72 \mathrm{mg}$, $1.1 \mathrm{mmol}$ ) in the presence of $5 \mathrm{~mol} \%(18 \mathrm{mg})$ of MPU in tetrahydrofuran at $50{ }^{\circ} \mathrm{C} .{ }^{b}$ General conditions: aldehyde $(1.0 \mathrm{mmol})$, methylcyanoacetate (110 mg, $1.1 \mathrm{mmol})$ in the presence of $5 \mathrm{~mol} \%(18 \mathrm{mg})$ of MPU in tetrahydrofuran at $50{ }^{\circ} \mathrm{C} .{ }^{c}$ Yields corresponding also to aldehyde conversion are based on ${ }^{1} \mathrm{H}$ NMR analysis of the isolated product obtained after $14 \mathrm{~h}$ of reaction time (Fig. S21-S49, ESI). TON (turnover number) = moles of desired product formed/moles of catalyst.

has occurred, the products might have been trapped within the pores due to their larger size as compared to the reactants and thus, no more reaction could occur. It should be noted that, a comparatively decreased yield of $80 \%$ has been observed with 2-naphthaldehyde given its larger molecular size $(5.6 \AA \times 7.5 \AA)$ as compared to benzaldehyde $(5.0 \AA \times 5.6 \AA)$ and its derivatives. While the molecular sizes of biphenyl-4-carboxaldehyde $(4.3 \AA \times$ $10.4 \AA)$ and 9-anthracenecarboxaldehyde $(6.4 \AA \times 9.6 \AA)$ are comparatively smaller than the larger micropores $(16 \AA)$ of the MPU, but their Knoevenagel products having larger molecular dimensions may not get out of the micropores if the reaction has occurred.

It is important to mention here that the reaction between benzaldehyde derivatives and malononitrile ( $1: 1.1$ molar ratio) can proceed without any catalyst in methanol/ethanol at $50{ }^{\circ} \mathrm{C}$ within $10 \mathrm{~h}$ (yield >90\%). However, the background reaction is comparatively much slower in the case of the reaction between benzaldehyde derivatives and methylcyanoacetate $(1: 1.1$ molar ratio) in methanol, and the yields are significantly improved using $5 \mathrm{~mol} \%$ the MPU catalyst (Table S4, ESI $\dagger$ ). High background reaction rate has also been observed in acetonitrile (MeCN) for the reaction between benzaldehyde and malononitrile giving a yield of $55 \%$ within $10 \mathrm{~h}$ at $50{ }^{\circ} \mathrm{C}$. These observations suggested that protic solvents and nitrogen containing aprotic solvents (such as MeCN and DMF) are not generally suitable for catalyst evaluation in the Knoevenagel reaction. Recent studies have shown that DMF as well as water can significantly promote the Knoevenagel condensation with quantitative yield. ${ }^{15}$

Further, the model Knoevenagel reaction performed in the presence of $5 \mathrm{~mol} \%$ of homogeneous base catalysts such as, pyrrole and piperidine/pyridine, in THF at $50{ }^{\circ} \mathrm{C}$ yielded $67 \%$ and 98\% respectively (Fig. S56 and S57, ESI $\dagger$ ), of the desired product within $10 \mathrm{~h}$. Also, imidazole/2-methylimidazole acts as a highly

efficient homogeneous catalyst in the Knoevenagel reaction. ${ }^{16}$ However, unlike heterogeneous solid catalysts, these homogeneous catalysts could not be recycled and reused, and therefore they are practically undesirable.

The catalytic activity of the MPU has also been assessed in the Knoevenagel condensation of methylcyanoacetate with aromatic aldehydes under the same optimal reaction conditions in THF. It has been observed that the yields are significantly reduced for benzaldehyde (60\%) and its derivatives with electron donating methyl and methoxy groups (Table 1). Whereas, excellent conversions above $80 \%$ have been observed for most of the benzaldehyde derivatives with electron withdrawing groups. As expected, reaction of methylcyanoacetate with 9-anthracenecarboxaldehyde and biphenyl-4-carboxaldehyde yielded no desired product due to their larger molecular size. These results strongly suggest that the MPU catalysed Knoevenagel reactions are closely dependent on pore size.

Increasing the molar reagent ratio of benzaldehyde and malononitrile to $1: 2$ with $5 \mathrm{~mol} \%$ of MPU at $50{ }^{\circ} \mathrm{C}$ in THF yielded 99\% of the desired product after $8 \mathrm{~h}$ (Fig. S16, ESI $\dagger$ ). Thus, the reagent ratio is also an important factor that should also be taken into consideration in the MPU catalysed Knoevenagel condensation.

To further explore the catalytic efficiency of the MPU towards other $\mathrm{C}-\mathrm{C}$ bond formation reactions, we have studied the Henry (nitroaldol) reaction of several aromatic aldehydes with nitromethane in the presence of $5 \mathrm{~mol} \%$ of activated MPU in methanol at $50{ }^{\circ} \mathrm{C}$ (Table 2). It was observed that, excellent conversions above $90 \%$ to the desired $\beta$-nitroalkanol products were obtained with nitrobenzaldehyde(s), 4-cyanobenyaldehyde and 4-carboxybenzaldehyde within $10 \mathrm{~h}$ (Fig. S17, ESI $\dagger$ ). However, no reaction has occurred with benzaldehyde, 2-naphthaldehyde, 4-anisaldehyde and biphenyl-4-carboxaldehyde under the same optimal reaction conditions. In general, the substrate scope of the MPU catalysed Henry reaction is limited to only benzaldehyde derivatives with electron withdrawing groups, however with significantly high yields (Table 2). Unlike the Knoevenagel reaction, the nitroaldol reaction between 4-nitrobenzaldehyde and nitromethane did not proceed in THF/MeCN signifying the importance of protic solvent in the MPU catalysed Henry reaction.

Hot filtration tests have been performed for the Knoevenagel and Henry reactions and the possibility of leaching of some of the

Table 2 Catalytic data of the MPU catalysed Henry (nitroaldol) reactions Aromatic aldehydes

Benzaldehyde 4-Nitrobenzaldehyde 3-Nitrobenzaldehyde 2-Nitrobenzaldehyde 4-Cyanobenzaldehyde 4-Carboxybenzaldehyde 4-Chlorobenzaldehyde 4-Tolualdehyde

${ }^{a}$ General conditions: aldehyde $(1.0 \mathrm{mmol})$, nitromethane $(610 \mathrm{mg}$, $10 \mathrm{mmol})$ in the presence of $5 \mathrm{~mol} \%(18 \mathrm{mg})$ of activated MPU in methanol at $50{ }^{\circ} \mathrm{C} .{ }^{b}$ Yields, corresponding also to aldehyde conversion are based on ${ }^{1} \mathrm{H}$ NMR analysis of the isolated product obtained after $10 \mathrm{~h}$ of reaction time (Fig. S50-S55, ESI). TON (turnover number) = moles of desired product formed/moles of catalyst. 
active sites from the solid catalyst to the liquid phase has been ruled out (see ESI $\dagger$ for details).

The catalyst was recycled and used for two consecutive runs with no significant loss in activity for the Knoevenagel reaction between 4-nitrobenzaldehyde with malononitrile and for the Henry reaction between 4-nitrobenzaldehyde with nitromethane (Fig. S18, see ESI $\dagger$ for details). The recovered catalyst has been characterized by FT-IR, PXRD, SEM, CHNS analysis and nitrogen sorption measurements (Fig. S11-S14 and Tables S1, S2, ESI $\dagger$ ). No significant changes have been observed in the FT-IR, PXRD, SEM and CHNS analysis data of the recycled MPU, only a slight decrease in BET specific surface area has been observed after the first and second catalytic run.

In conclusion, we have reported a catalytically active new microporous polyurethane material with sponge like morphology obtained by solvothermal synthesis in DMSO. Due to its confined microporosity and the presence of mildly basic urethane (carbamate) functional groups along the pore walls, the MPU showed catalytic efficiency with pronounced size selectivity in the Knoevenagel condensation of aromatic aldehydes with malononitrile or methylcyanoacetate. In the related nitroaldol (Henry) reaction involving nitromethane as the nucleophile, the catalyst showed high substrate selectivity as significant yields of $\beta$-nitroalkanol product could only be obtained with benzaldehyde derivatives having electron withdrawing groups. Overall, this work represents the first example of heterogeneous catalysis by a porous polyurethane material which will encourage the development of new functional porous polyurethanes for the catalysis of several other important reactions.

\section{Notes and references}

1 S.-Y. Ding and W. Wang, Chem. Soc. Rev., 2013, 42, 548; X. Feng, X. Ding and D. Jiang, Chem. Soc. Rev., 2012, 41, 6010; Z. Xiang, D. Cao and L. Dai, Polym. Chem., 2015, 6, 1896.

2 B. G. Hauser, O. K. Farha, J. Exley and J. T. Hupp, Chem. Mater., 2013, 25, 12; W. Lu, D. Yuan, D. Zhao, C. I. Schilling, O. Plietzsch, T. Muller, S. Braese, J. Guenther, J. Bluemel, R. Krishna, Z. Li and H.-C. Zhou, Chem. Mater., 2010, 22, 5964; A. Bhunia, I. Boldog, A. Möller and C. Janiak, J. Mater. Chem. A, 2013, 1, 14990; A. Bhunia, V. Vasylyeva and C. Janiak, Chem. Commun., 2013, 49, 3961.

3 P. Kaur, J. T. Hupp and S. T. Nguyen, ACS Catal., 2011, 1, 819; Y. Zhang and S. N. Riduan, Chem. Soc. Rev., 2012, 41, 2083.

4 S. Wan, J. Guo, J. Kim, H. Ihee and D. Jiang, Angew. Chem., Int. Ed., 2008, 120, 8958; S. Wan, J. Guo, J. Kim, H. Ihee and D. Jiang, Angew. Chem., Int. Ed., 2009, 48, 5439; E. L. Spitler and W. R. Dichtel, Nat. Chem., 2010, 2, 672; X. Ding, L. Chen, Y. Honsho, X. Feng,
O. Saengsawang, J. Guo, A. Saeki, S. Seki, S. Irle, S. Nagase, V. Parasuk and D. Jiang, J. Am. Chem. Soc., 2011, 133, 14510.

5 D. F. Perepichka and F. Rosei, Science, 2009, 323, 216; J. F. Dienstmaier, D. D. Medina, M. Dogru, P. Knochel and T. Bein, ACS Nano, 2012, 6, 7234; A. Lyapin, S. Reichlmaier, W. M. Heckl and M. Lackinger, ACS Nano, 2011, 5, 9737.

6 J. Shi, Y. Wang, W. Yang, Y. Tang and Z. Xie, Chem. Soc. Rev., 2015, 44, 8877; A. Dhakshinamoorthy, M. Opanasenko, J. Cejka and H. Garcia, Catal. Sci. Technol., 2013, 3, 2509; A. H. Chughtai, N. Ahmad, H. A. Younus, A. Laypkov and F. Verpoort, Chem. Soc. Rev., 2015, 44, 6804; J. Liu, L. Chen, H. Cui, J. Zhang, L. Zhang and C.-Y. Su, Chem. Soc. Rev., 2014, 43, 6011.

7 F. Freeman, Chem. Rev., 1980, 80, 329; L. F. Tietze, Chem. Rev., 1996, 96, 115.

8 S. Hasegawa, S. Horike, R. Matsuda, S. Furukawa, K. Mochizuki, Y. Kinoshita and S. Kitagawa, J. Am. Chem. Soc., 2007, 129, 2607; Q. R. Fang, S. Gu, J. Zheng, Z. B. Zhuang, S. L. Qiu and Y. S. Yan, Angew. Chem., Int. Ed., 2014, 53, 2878; J. Kim, A. Vimont, M. Daturi, C. Serre and G. Férey, Angew. Chem., Int. Ed., 2008, 47, 4144; U. P. N. Tran, K. K. A. Le and N. T. S. Phan, ACS Catal., 2011, 1, 120; A. Karmakar, C. L. Oliver, S. Roy and L. Öhrströma, Dalton Trans., 2015, 44, 10156; A. Karmakar, S. Hazra, M. Fátima, C. G. da Silva, A. Paul and A. J. L. Pombeiro, CrystEngComm, 2016, 18, 1337.

9 R. Xing, H. Wu, X. Li, Z. Zhao, Y. Liu, L. Chen and P. Wu, J. Mater. Chem., 2009, 19, 4004; Z. Gao, J. Zhou, F. Cui, Z. H. Yan Zhu and J. Shi, Dalton Trans., 2010, 39, 11132; F. Shang, J. Sun, S. Wu, Y. Yang, Q. Kan and J. Guan, Microporous Mesoporous Mater., 2010, 134, 44; S. H. Zhao, X. J. Wang and L. W. Zhang, RSC Adv., 2013, 3, 11691; A. Villa, J. P. Tessonnier, O. Majoulet, D. S. Su and R. Schlogt, ChemSusChem, 2010, 3, 241; J. Xu, Y. Wang, J.-K. Shang, Q. Jiang and Y.-X. Li, Catal. Sci. Technol., DOI: 10.1039/c5cy01747e; J. Xu, T. Chen, J.-K. Shang, K.-Z. Long and Y.-X. Li, Microporous Mesoporous Mater., 2015, 211, 105; N. Kan-nari, S. Okamura, S.-I. Fujita, J.-I. Ozaki and M. Arai, Adv. Synth. Catal., 2010, 352, 1476.

10 (a) Q. Fang, S. Gu, J. Zheng, Z. Zhuang, S. Qiu and Y. Yan, Angew. Chem., Int. Ed., 2014, 53, 2878; (b) V. M. Suresh, S. Bonakala, H. S. Atreya, S. Balasubramanian and T. K. Maji, ACS Appl. Mater. Interfaces, 2014, 6, 4630.

11 J. Guan, K. L. Fujimoto, M. S. Sacks and W. R. Wagner, Biomaterials, 2005, 26, 3961; Y.-C. Wang, F. Fang, Y.-K. Wu, X.-L. Ai, T. Lan, R.-C. Liang, Y. Zhang, N. M. Trishul, M. He, C. You, C. Yu and H. Tan, RSC Adv., 2016, 6, 3840.

12 X. Wang and E. Ruckenstein, Biotechnol. Prog., 1993, 9, 661; A. Koh, Y. Lu and M. H. Schoenfisch, Anal. Chem., 2013, 85, 10488; X. Zhang, Z. Du, W. Zou, H. Li, C. Zhang, S. Li and W. Guo, RSC Adv., 2015, 5,65890 .

13 M. Thommes, K. Kaneko, A. V. Neimark, J. P. Olivier, F. RodriguezReinoso, J. Rouquerol and K. S. W. Sing, Pure Appl. Chem., 2015, 87, 1051; K. S. W. Sing, D. H. Everett, R. A. W. Haul, L. Moscou, R. A. Pierotti, J. Rouquerol and T. Siemieniewska, Pure Appl. Chem., 1985, 57, 603.

14 A. C. Sudik, A. P. Cote, A. G. Wong-Foy, M. O'Keeffe and O. M. Yaghi, Angew. Chem., Int. Ed., 2006, 45, 2528, and references therein.

15 (a) Y. Luan, Y. Qi, H. Gao, R. S. Andriamitantsoa, N. Zheng and G. Wang, J. Mater. Chem. A, 2015, 3, 17320; (b) M. H. Moemeni, M. A. Amrollahi and F. Tamaddon, Bulg. Chem. Commun., 2015, 47, 7.

16 A. Pande, K. Ganesan, A. K. Jain, P. K. Gupta and R. C. Malhotra, Org. Process Res. Dev., 2005, 9, 133. 